\title{
Molecular epidemiological studies on animal trypanosomiases in Ghana
}

\author{
Jesca Nakayima ${ }^{1,2}$, Ryo Nakao ${ }^{1}$, Andy Alhassan $^{3}$, Charles Mahama ${ }^{3}$, Kofi Afakye $^{3}$ and Chihiro Sugimoto ${ }^{\text {1* }}$
}

\begin{abstract}
Background: African trypanosomes are extracellular protozoan parasites that are transmitted between mammalian hosts by the bite of an infected tsetse fly. Human African Trypanosomiasis (HAT) or sleeping sickness is caused by Trypanosoma brucei rhodesiense or T. brucei gambiense, while African Animal Trypanosomiasis (AAT) is caused mainly by T. vivax, T. congolense, T. simiae, T. evansi and T. brucei brucei. Trypanosomiasis is of public health importance in humans and is also the major constraint for livestock productivity in sub-Saharan African countries. Scanty information exists about the trypanosomiasis status in Ghana especially regarding molecular epidemiology. Therefore, this study intended to apply molecular tools to identify and characterize trypanosomes in Ghana.

Methods: A total of 219 tsetse flies, 248 pigs and 146 cattle blood samples were collected from Adidome and Koforidua regions in Ghana in 2010. Initial PCR assays were conducted using the internal transcribed spacer one (ITS1) of ribosomal DNA (rDNA) primers, which can detect most of the pathogenic trypanosome species and T. vivax-specific cathepsin L-like gene primers. In addition, species- or subgroup-specific PCRs were performed for T. $b$. rhodesiense, T. b. gambiense, T. evansi and three subgroups of T. congolense.

Results: The overall prevalence of trypanosomes were $17.4 \%$ (38/219), 57.5\% (84/146) and 28.6\% (71/248) in tsetse flies, cattle and pigs, respectively. T. congolense subgroup-specific PCR revealed that T. congolense Savannah (52.6\%) and T. congolense Forest (66.0\%) were the endemic subgroups in Ghana with $18.6 \%$ being mixed infections. T. evansi was detected in a single tsetse fly. Human infective trypanosomes were not detected in the tested samples.

Conclusion: Our results showed that there is a high prevalence of parasites in both tsetse flies and livestock in the study areas in Ghana. This enhances the need to strengthen control policies and institute measures that help prevent the spread of the parasites.
\end{abstract}

Keywords: Trypanosomiasis, Human African Trypanosomiasis, Ghana, PCR

\section{Background}

African trypanosomes are extracellular protozoan parasites that are transmitted between mammalian hosts by the bite of an infected tsetse fly. Human African Trypanosomiasis (HAT) or sleeping sickness is caused by Trypanosoma brucei rhodesiense or T. brucei gambiense. The two subspecies are geographically distinct; the separation can be approximated to T. b. gambiense present west of the Great Rift Valley and T. $b$. rhodesiense to the east [1]. Livestock is a major reservoir of HAT caused by T. b. rhodesiense [2]. Trypanosomiasis in livestock has a

\footnotetext{
* Correspondence: sugimoto@czc.hokudai.ac.jp

'Division of Collaboration and Education, Research Center for Zoonosis Control, Hokkaido University, Kita 20, Nishi 10, Kita-kuSapporo, Hokkaido 001-0020, Japan

Full list of author information is available at the end of the article
}

significant impact on agricultural productivity and is caused mainly by $T$. congolense, $T$. vivax, $T$. simiae, $T$. evansi and T. brucei brucei [3]. T. evansi, which is most closely related to $T . b$. brucei, is not transmitted by tsetse flies but mechanically transmitted by biting flies [4].

Scanty information exists about the trypanosomiasis status in Ghana, especially regarding molecular epidemiology. In 2003, a 10-month-old Ghanaian boy recovered from a T. brucei infection [5]. The identity of the trypanosome was determined by DNA extraction from the archived stained blood slides followed by sequential application of PCR assays that are specific for the order, subgenus, species and subspecies. The epidemiology of bovine trypanosomosis was investigated in two districts (Savelugu and West Mamprusi) of Northern Ghana with

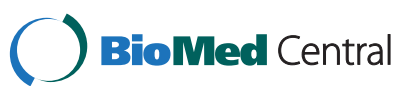


different land use and environmental characteristics [6]. The land use intensity and environmental change was suspected to be higher in the Savelugu district. The parasitological and serological prevalence of bovine trypanosomoses was significantly higher in West Mamprusi (16\% and 53\%, respectively) than in Savelugu district ( $8 \%$ and $24 \%$, respectively). A cross-sectional entomological survey conducted along the White Volta River and its tributaries confirmed the presence of only Glossina palpalis gambiensis and G. tachinoides [6].

Prohibitive costs and widespread perception that diagnostic PCR technology is complex slows down its adoption. For instance, in the case of the species-specific diagnosis, five different PCR assays per sample would be required to screen for $T$. vivax, T. brucei, T. congolense, $T$. simiae and T. evansi. The tests would consume considerable time, labour and costs. If the cost constraints are overcome, efforts should be directed towards minimizing sample handling and decreasing the possibility of contamination, at the same time raising the potential to function efficiently in the hands of moderately trained technical staff [7]. The use of the internal transcribed spacer one (ITS1) of ribosomal DNA (rDNA) based primers as a universal diagnostic test for all pathogenic trypanosomes considerably overcomes the above constraints. ITS1 PCR detects eleven pathogenic Trypanosoma species in a single PCR, thereby saving time and costs as compared to species-specific PCR. The expected products of ITS1 PCR are species-specific with size differences as indicated: members of subgenus Trypanozoon (T. b. brucei, T. evansi, T. b. rhodesiense and T. b. gambiense) a constant product of approximately $480 \mathrm{bp} ; \quad T$. congolense Savannah subgroup $700 \mathrm{bp}, T$. congolense Kilifi subgroup 620 bp, T. congolense Forest subgroup $710 \mathrm{bp}, T$. simiae $400 \mathrm{bp}, T$. simiae tsavo $370 \mathrm{bp}$, T. godfreyi $300 \mathrm{bp}$, and T. vivax 250 bp [8-11]. By reducing the number of reactions per sample, the test effectively reduces the cost of PCR and time required for diagnosis.

Previous research on trypanosomiasis in Ghana [6] has employed mainly parasitological and serological tools, which are less accurate. Progress in diagnosis, treatment and epidemiology of trypanosomiasis depends on the existence of specific and sensitive diagnostic tools. Inherent shortcomings of serologic and parasitologic diagnostic methods can be overcome by molecular techniques. Accurate and efficient identification of the trypanosome species present in the fly vectors and vertebrate hosts is vital to assess the disease risk in Ghana.

\section{Methods}

\section{Study area}

The study was conducted on tsetse flies, pig and cattle blood samples collected from Adidome (Latitude: $6^{\circ} 4$
26.6592" and Longitude: $\left.0^{\circ} 29^{\prime} 59.2512 "\right)$ and cattle blood from Koforidua (Latitude: $6^{\circ} 5^{\prime} 14.9316^{\prime \prime}$ and Longitude: $0^{\circ} 15^{\prime} 44.82^{\prime \prime}$ ) areas in Ghana (Figure 1), following an outbreak of trypanosomiasis in livestock in these areas in 2010 (A. Alhassan, personal communication).

\section{Tsetse flies}

Tsetse fly samples were collected from Adidome in Ghana. Typically biconical traps were used to catch the tsetse and each trap was baited with two types of chemical attractant: acetone and 3-n-propylphenol 4-methyl-phenol and octenol at a ratio of 1:8:4 [12]. Effort was made to situate the traps under the shade of trees to avoid undue fly mortality and flies were collected every morning. The tsetse flies were sexed and preserved in silica gel until DNA was extracted. A total of 219 tsetse flies were analysed.

\section{Animal blood}

Blood samples were collected from 248 pigs and 108 cattle from Adidome and 38 cattle from Koforidua. Approximately $10 \mathrm{ml}$ of whole blood was withdrawn into a heparinised vaccutainer from the jugular vein. Subsequently $100 \mu \mathrm{l}$ was applied directly onto Flinders Technology Associates filter paper FTA $^{\circledR}$ Cards (Whatman International Ltd., Abington, Cambridge,

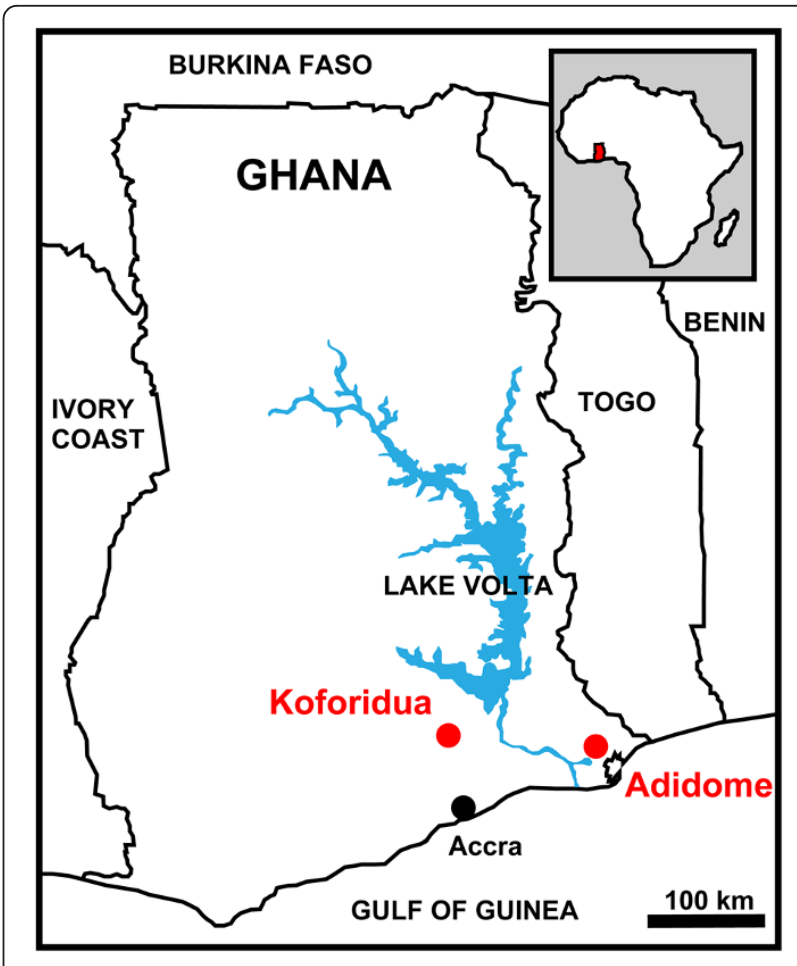

Figure 1 Map of Ghana showing the sites where sampling was conducted. Tsetse flies, cattle and pig blood were collected from Koforidua and Adidome areas in the south of the country. Sample sites for this study are indicated in red. 
UK), which were allowed to dry thoroughly prior to storage at room temperature. Ethical approval was obtained by the Research Centre for Zoonosis Control, Hokkaido University, Japan. The study was conducted adhering to this institution's guidelines for animal husbandry. Verbal informed consent was obtained from each owner of livestock prior to the extraction of blood samples by the field team.

\section{DNA extraction}

Tsetse flies were homogenized by Micro Smash MS100R (TOMY, Tokyo, Japan) in the presence of stainless steel beads (1.0 mm in diameter) for $2 \mathrm{~min}$ at 2,500 rpm, followed by DNA extraction with DNAzol (Invitrogen, Carlsbad, CA). The tsetse homogenate was mixed with $1 \mathrm{ml}$ DNAzol reagent prior to the addition of $100 \%$ ethanol. The sample was shaken vigorously and left at room temperature for $5 \mathrm{~min}$ followed by two washes with $75 \%$ ethanol. DNA was precipitated by centrifugation at $12,000 \mathrm{~g}$ for $10 \mathrm{~min}$, solubilised in $200 \mu \mathrm{l}$ of $8 \mathrm{mM}$ $\mathrm{NaOH}$. The solution was then neutralised by adding $2 \mu \mathrm{l}$ of $1 \mathrm{M}$ HEPES and was stored at $-20^{\circ} \mathrm{C}$ prior to further processing. DNA extraction from FTA cards by punching $2 \mathrm{~mm}$ discs from the sample-saturated cards using an FTA punch and washing three times with distilled water and eluting the DNA in $100 \mu$ l of PCR buffer (Promega, Madison, WI).

\section{PCR}

All PCR reactions were conducted using Amplitaq Gold $^{\circledR} 360$ reagent (Applied Biosystems, Foster City, $\mathrm{CA})$ in a $20 \mu \mathrm{l}$ reaction volume. The initial PCR screening was performed using ITS1 primers [8] to detect multiple Trypanosoma species in a single reaction. However, this primer set was reported to have a low sensitivity against $T$. vivax $[8,11,13]$ presumably because of the low level of sequence similarity between different $T$. vivax isolates. To overcome this problem, this study employed T. vivax-specific PCR using the primers TviCatL1 and DTO155 [14]. The samples positive for Trypanozoon by ITS1 PCR were further tested by species-specific PCR to characterize T. b. brucei, T. evansi, T. b. gambiense and T. $b$. rhodesiense. When ITS1 PCR generated the PCR products of approximately $700 \mathrm{bp}, T$. congolense subgroup-specific PCR were conducted to distinguish between Savannah, Forest and Kilifi. All the primer sets employed in this study are listed in Table 1. The PCR products were electrophoresed in a $1.5 \%$ agarose gel stained with Gel-Red TM (Biotium, Hayward, CA) and were visualized under UV light.

\section{Sequencing analysis}

The amplified products of ITS1 PCR were randomly selected (3-5 samples per each amplicon size) and subjected to direct sequencing. The products were treated with ExoSAP-IT (USB Corporation, Cleveland, $\mathrm{OH}$ ) and sequenced using the BigDye Terminator version 3.1 Cycle Sequencing Kit (Applied Biosystems) and an ABI Prism 3130x genetic analyzer (Applied Biosystems) according to the manufacturer's instructions. The DNA sequences obtained were submitted to the DNA Data Bank of Japan (DDBJ) (http://www.ddbj.nig.ac.jp) under accession nos AB742529 to AB742533.

\section{Results}

\section{ITS1 \& T. vivax-specific PCR}

A total of 613 samples including 219 tsetse flies, 146 cattle and 248 pigs blood samples were subjected to ITS1 PCR screening for different trypanosome species and the prevalence of the parasites are indicated in Table 2. Despite that ITS1 PCR detected only 36 positives for $T$. vivax (data not shown), T. vivax-specific PCR using cathepsin L-like primers detected 21, 37 and 47 positives in tsetse flies, cattle and pigs, respectively. The overall prevalence of trypanosomes were $17.4 \%$ (38/219), 57.5\% $(84 / 146)$ and $28.6 \%(71 / 248)$ in tsetse flies, cattle and pigs, respectively. The trypanosome prevalence was lower in the tsetse flies than in the vertebrate hosts. The predominant species in vertebrate hosts was $T$. vivax, while in tsetse flies $T$. congolense was detected as a predominant species followed by $T$. vivax. In all samples $T$. simiae was the least common. Figure 2 indicates the frequencies of mixed infection in each sample. The mixed infections with two different Trypanosoma species were observed in 9, 18 and 28 individuals of tsetse flies, cattle and pigs, respectively. Three different parasite species were detected in 6 cattle and 7 pig blood samples.

\section{ITS1 sequencing analysis}

A total of five different sequences (249, 387, 470, 475 and 725 bp in size) were recovered by sequencing analysis of ITS1 PCR products. These sequences were compared with those available in public databases by using nucleotide BLAST at NCBI website (http://blast.ncbi. nlm.nih.gov/Blast.cgi). The sequences of the 249- and 475-bp products were $100 \%$ identical to $T$. vivax (GenBank accession number: HE573019) and T. evansi (AY912278), respectively. The sequences of the 387-, 470- and 725-bp products showed 99\%, 98\% and 96\% identities with $T$. simiae (AB625446), T. brucei (AC159414) and T. congolense (TCU22319), respectively.

\section{PCR for human infective trypanosomes}

The samples positive for Trypanozoon by ITS1 PCR were subjected to PCR assays specific for $T$. b. rhodesiense and T. b. gambiense. All the reactions were negative and human infective trypanosomes were not detected in the tested samples. 
Table 1 PCR primers used in the present study

\begin{tabular}{|c|c|c|c|c|c|c|}
\hline Organism & Target gene & Primer & Sequence (5' to $\left.3^{\prime}\right)$ & $\begin{array}{l}\text { Amplicon } \\
\text { size (bp) }\end{array}$ & $\begin{array}{l}\text { Annealing } \\
\text { temperature } \\
\left({ }^{\circ} \mathrm{C}\right)\end{array}$ & Reference \\
\hline \multirow[t]{2}{*}{ Trypanosoma spp. } & \multirow[t]{2}{*}{ ITS1 rDNA } & ITS1 CF & CCGGAAGTTCACCGATATTG & \multirow[t]{2}{*}{ Variable } & \multirow[t]{2}{*}{58} & \multirow[t]{2}{*}{ [8] } \\
\hline & & ITS1 BR & TTGCTGCGTTCTTCAACGAA & & & \\
\hline \multirow[t]{2}{*}{ T. congolense Kilifi } & \multirow{2}{*}{$\begin{array}{l}\text { Satellite DNA } \\
\text { monomer }\end{array}$} & TCK 1 & GTG CCC AAA TTT GAA GTG AT & \multirow[t]{2}{*}{294} & \multirow[t]{2}{*}{55} & \multirow[t]{2}{*}{ [15] } \\
\hline & & TCK 2 & ACT CAA AAT CGT GCA CCT CG & & & \\
\hline \multirow[t]{2}{*}{ T. congolense Forest } & \multirow{2}{*}{$\begin{array}{l}\text { Satellite DNA } \\
\text { monomer }\end{array}$} & TCF 1 & GGA CAC GCC AGA AGG TAC TT & \multirow[t]{2}{*}{350} & \multirow[t]{2}{*}{55} & \multirow[t]{2}{*}{ [15] } \\
\hline & & TCF 2 & GTT CTC GCA CCA AAT CCA AC & & & \\
\hline \multirow{2}{*}{$\begin{array}{l}\text { T. congolense } \\
\text { Savannah }\end{array}$} & \multirow{2}{*}{$\begin{array}{l}\text { Satellite DNA } \\
\text { monomer }\end{array}$} & TCS 1 & CGA GAA CGG GCA CTT TGC GA & \multirow[t]{2}{*}{316} & \multirow[t]{2}{*}{55} & \multirow[t]{2}{*}{ [15] } \\
\hline & & TCS 2 & GGA CAA AGA AAT CCC GCA CA & & & \\
\hline \multirow[t]{2}{*}{ T. vivax } & \multirow{2}{*}{$\begin{array}{l}\text { Cathepsin } \\
\text { L-like gene }\end{array}$} & DTO 155 & TTAAAGCTTCCACGAGTTCTTGATGATCCAGTA & \multirow[t]{2}{*}{177} & \multirow[t]{2}{*}{65} & \multirow[t]{2}{*}{ [14] } \\
\hline & & TviCatL1 & GCCATCGCCAAGTACCTCGCCGA & & & \\
\hline \multirow[t]{2}{*}{ T. evansi } & \multirow{2}{*}{$\begin{array}{l}\text { RoTat1.2 VSG } \\
\text { gene }\end{array}$} & TeRoTat $920 \mathrm{~F}$ & CTGAAG AGGTTGGAAATGGAGAAG & \multirow[t]{2}{*}{151} & \multirow[t]{2}{*}{58} & \multirow[t]{2}{*}[16]{} \\
\hline & & TeRoTat 1070R & GTTTCGGTGGTTCTGTTGTTG TTA & & & \\
\hline \multirow[t]{2}{*}{ T. b. rhodesiense } & \multirow[t]{2}{*}{ SRA gene } & Forward & ATAGTGACAAGATGCGTACTCAACGC & \multirow[t]{2}{*}{284} & \multirow[t]{2}{*}{68} & \multirow[t]{2}{*}[17]{} \\
\hline & & Reverse & AATGTGTTCGAGTACTTCGGTCACGCT & & & \\
\hline \multirow[t]{2}{*}{ T. b. gambiense } & \multirow[t]{2}{*}{ TgsGP gene } & sense & GCTGCTGTGTTCGGAGAGC & 308 & 63 & [18] \\
\hline & & anti-sense & GCCATCGTGCTTGCCGCTC & & & \\
\hline
\end{tabular}

\section{T. evansi-specific PCR}

Having detected $T$. evansi in a tsetse fly by sequence analysis of ITS1 PCR product, we conducted T. evansispecific PCR using RoTat 1.2 VSG gene primers for the samples positive for Trypanozoon by ITS1 PCR. However, all the samples including one positive for T. evansi by sequencing analysis, were negative.

\section{T. congolense subgroup-specific PCR}

The samples positive for $T$. congolense by ITS1 PCR were subjected to $T$. congolense subgroup-specific PCRs to ascertain the subgroups endemic in Ghana. Out of 97 samples, 51 and 64 samples were tested positive for subgroups Savannah and Forest, respectively (Table 3). The Kilifi subgroup was not detected in the tested samples. The Forest subgroup was predominant in tsetse flies and pigs, while the Savannah subgroup was predominant in cattle. Mixed infections between subgroups Savannah and Forest were detected in 3 cattle and 15 pig samples.

\section{Discussion}

There are 11 different pathogenic trypanosomes known to exist in Africa. The primers ITS1 CF and ITS1 BR, previously designed to amplify the ITS1 region of all pathogenic trypanosome species, give PCR products with species-specific sizes and thus enable multiplex detection of different parasite species [8]. This assay system was successfully applied to identify and characterize trypanosomes in Ghana with some limitations discussed below.

A total of 613 samples were screened for trypanosome infections by ITS1 PCR, of which 59 samples tested positive for Trypanozoon. These were further tested for the presence of human infective trypanosomes, however, none of them were positive. Since the livestock and wild animals are known to act as reservoirs for HAT [19-21], it is important to continue active surveillance in animals to understand the transmission cycle of HAT in endemic areas.

T. evansi was detected in a single tsetse fly sample despite being classified as non tsetse- transmitted

Table 2 Overall prevalence of trypanosomes

\begin{tabular}{|c|c|c|c|c|c|c|}
\hline \multirow[t]{2}{*}{ Sample type } & \multirow{2}{*}{$\begin{array}{l}\text { Total no. of } \\
\text { samples tested }\end{array}$} & \multicolumn{3}{|c|}{ ITS1 PCR } & \multirow[t]{2}{*}{ T. vivax- specific PCR } & \multirow[t]{2}{*}{ No. of positives } \\
\hline & & T. congolense & T. simiae & Trypanozoon & & \\
\hline Tsetse flies & 219 & 23 & 0 & 3 & 21 & 47 \\
\hline Cattle & 146 & 36 & 4 & 37 & 37 & 114 \\
\hline Pigs & 248 & 38 & 9 & 19 & 47 & 113 \\
\hline Total & 613 & 97 & 13 & 59 & 105 & \\
\hline
\end{tabular}



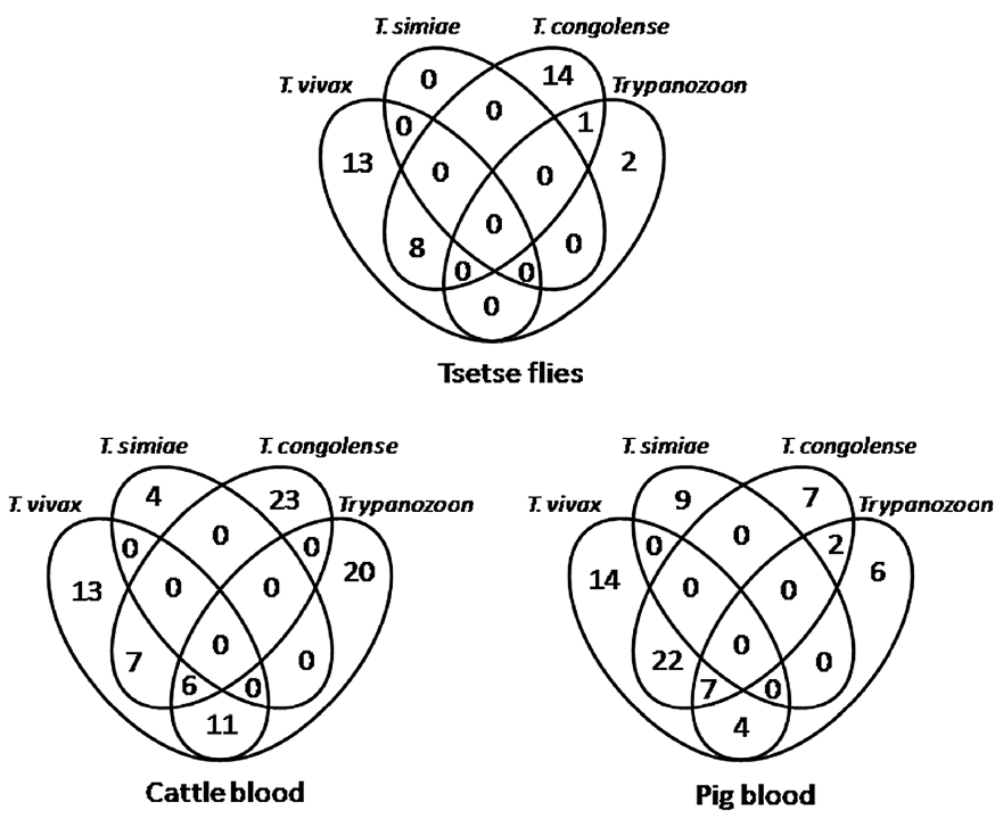

Figure 2 Status of mixed infections between different Trypanosoma spp. Trypanozoon, T. congolense and T. simiae were screened using ITS1-PCR while T. vivax was screened using T. vivax-specific cathepsin L-like PCR.

trypanosomes (NTTT) [4]. This parasite is known to be mechanically transmitted by biting flies such as the genera Tabanus and Stomoxys, enabling a world-wide distribution even outside the tsetse belt of Africa. Thus, the detection of $T$. evansi in a tsetse fly might reflect the existence of carrier animals in the vicinity of tsetse flies. Since the ITS1 PCR product size of T. evansi is similar to one of T. brucei, sequencing analysis was key to differentiating between the two infections. Furthermore, $T$. evansi-specific PCR based on RoTat 1.2 VSG gene failed in this study and thus might not be reliable in epidemiological surveys and diagnosis of $T$. evansi as reported elsewhere [22]. These problems make it difficult to assess the possibility of $T$. evansi endemicity in Ghana.

$T$. congolense subgroup-specific PCR did not detect Kilifi in Ghana (Table 3). This result seems natural considering that it is thought to be an East African subgroup first isolated from livestock in 1982 on a ranch at Kilifi on the Kenyan coast [23]. Both Savannah and Forest were the endemic subgroups in Ghana and mixed infections between the two subgroups were recorded at $18.6 \%$. The Forest subgroup could be the most prevalent in Ghana possibly because of the humid equatorial forest ecosystems of West Africa. Considering that the Savannah subgroup was reported to be more virulent than the Forest subgroup [24], a high prevalence of the Savannah subgroup in cattle may indicate that the parasites were introduced recently into the tested herds.

The high prevalence of $T$. vivax corroborates other findings in domestic animals [25] as well as wild animals $[20,26,27]$. This may result from the level of pathogenicity of this trypanosome, which is generally low and better controlled by animals [28], and/or from the mechanical transmission, which has been reported in $T$. vivax, $T$. evansi and to a certain extent $T$. congolense [29]. The lower prevalence of $T$. congolense with respect to $T$. vivax in animals may result from higher parasitemia in $T$. congolense infections, accompanied by serious anaemia, which leads to the rapid death of the host animal $[30,31]$. The very low prevalence of $T$. simiae as previously reported in pigs $[19,32]$ and wild animals $[26,27]$ may indicate a low transmission of the parasite in the studied localities of Ghana and is also likely due to its high pathogenicity because pigs infected with this trypanosome species would not probably survive the acute, severe and fatal nature of this parasite.

Table $3 T$. congolense subgroup-specific PCR results

\begin{tabular}{|c|c|c|c|c|c|}
\hline Sample type & Total no. of samples tested & Savannah & Forest & Kilifi & Mixed infection \\
\hline Tsetse flies & 23 & 0 & 23 & 0 & 0 \\
\hline Cattle & 36 & 36 & 3 & 0 & 3 \\
\hline Pigs & 38 & 15 & 38 & 0 & 15 \\
\hline Total & 97 & 51 & 64 & 0 & 18 \\
\hline
\end{tabular}


In large-scale epidemiological studies, FTA cards are becoming increasingly popular for the rapid collection and archiving of a large number of samples. However, there are some difficulties in the downstream processing of these cards, which is essential for the accurate diagnosis of infection. It should be noted that the use of FTA cards for sample preparation has some limitations. The main one is that at low trypanosome intensities (i.e. animals with a very low level infection and chronic infections) there is an uneven distribution of parasite DNA on the cards and that some positive cards can give a negative result because the wrong part of the card was sampled $[33,34]$. This has an implication that the results presented from the FTA cards may actually be underestimates of the true prevalence. Therefore, in order to decrease the probability of false negative results from using a single disc, examination of more discs would give more accurate estimation of the disease prevalence $[33,34]$.

The mixed infections with two or three different Trypanosoma species were commonly observed in both cattle and pigs (Figure 2). These co-infections have also been documented previously with multiple trypanosome species [35,36]. This molecular epidemiological work confirmed the abundance of mixed infections in the field, which could not have been detected by the classical parasitological methods. Mixed infections could be a result of high chances of trypanosome infections by tsetse flies and/or a case of chronic infection in susceptible hosts. This points towards the severity of AAT, exacerbating animal losses incurred by farmers such that deliberate efforts need to be in place to control tsetse flies in order to break the transmission cycle to domestic animals and thus improve livestock production and productivity in the endemic area. AAT risk is usually linked to the density of the vector and the trypanosome infection rates [36].

\section{Conclusion}

Trypanosoma parasites circulate within Ghana at high prevalence in vertebrate hosts and tsetse flies. T. brucei was highly prevalent in the study areas but no human infective trypanosomes were detected. In livestock, the endemic $T$. congolense subgroups were Savannah and Forest while Kilifi was not detected. T. simiae was detected only in pig and cattle samples. PCR results indicated high prevalence of T. vivax in both tsetse flies and vertebrate hosts. T. evansi was detected in a tsetse fly sample. Our results provide insight into the epidemiology of trypanosomiasis in Ghana based on highly sensitive and specific molecular techniques. Intervention to control the disease by the various stakeholders is highly recommended.
Competing interests

The authors declare that they have no competing interests.

\section{Authors' contributions}

JN performed PCR and sequencing, conducted data analysis and drafted the manuscript. RN guided and directed the study, AA collected the samples, CM \& KA participated in sample collection and CS supervised the study. All authors read and approved the final manuscript.

\section{Acknowledgment}

This work was supported by the program of Funding Research Center for Emerging and Re-emerging Infectious Disease from Ministry of Education, Culture, Sports, Science and Technology of Japan (MEXT).

\section{Author details}

${ }^{1}$ Division of Collaboration and Education, Research Center for Zoonosis Control, Hokkaido University, Kita 20, Nishi 10, Kita-kuSapporo, Hokkaido 001-0020, Japan. ${ }^{2}$ National Livestock Resources Research Institute (NaLIRRI), P. O Box 96, Tororo, Uganda. ${ }^{3}$ Veterinary Services Department, P.O Box M161, Accra, Ghana.

Received: 15 June 2012 Accepted: 20 September 2012

Published: 1 October 2012

\section{References}

1. Thomson R, Molina-Portela P, Mott H, Carrington M, Raper J: Hydrodynamic gene delivery of baboon trypanosome lytic factor eliminates both animal and human infective African trypanosomes. PNAS 2009, 106:19509-19514.

2. Fevre EM, Picozzi K, Jannin J, Welburn SC, Maudlin I: Human African trypanosomiasis: Epidemiology and control. Adv Parasitol 2006, 61:167-221.

3. Van den Bossche P: Some general aspects of the distribution and epidemiology of bovine trypanosomosis in southern africa. Int J Parasitol 2001, 31:592-598.

4. Food and Agriculture Organization (FAO): Non tsetse-transmitted trypanosomoses. http://www.fao.org.

5. Deborggraeve S, Koffi M, Jamonneau V, Bonsu FA, Queyson R, Simarro PP, Herdewijn P, Büscher P: Molecular analysis of archived blood slides reveals an atypical human Trypanosoma infection. Diagn Microbiol Infect Dis 2008, 61:428-433.

6. Mahama Cl, Desquesnes M, Dia ML, Losson B, De Deken R, Geerts S: A cross-sectional epidemiological survey of bovine trypanosomosis and its vectors in the Savelugu and West Mamprusi districts of northern Ghana. Vet Parasitol 2004, 122:1-13.

7. Eisler MC, Dwinger RH, Majiwa PAO, Picozzi K: Diagnosis and Epidemiology of African Animal Trypanosomiasis. In The Trypanosomiases. Edited by Maudlin I, Holmes PH. Miles MA: CABI Publishing; 2004:253-267.

8. Njiru ZK, Constantine CC, Guya S, Crowther J, Kiragu JM, Thompson RCA, Da'vila AMR: The use of ITS1 rDNA PCR in detecting pathogenic African trypanosomes. Parasitol Res 2005, 95:186-192.

9. Adams ER, Malele II, Msangi AR, Gibson WC: Trypanosome identification in wild tsetse populations in Tanzania using generic primers to amplify the ribosomal RNA ITS-1 region. Acta Trop 2006, 100:103-109.

10. Cox A, Tilley A, McOdimba F, Fyfe J, Eisler M, Hide G, Welburn S: A PCR based assay for detection and differentiation of African trypanosome species in blood. Exp Parasitol 2005, 111:24-29.

11. Desquesnes M, Mclaughlin G, Zoungrana A, DÁvila AMR: Detection and identification of Trypanosoma of African livestock through a single PCR based on internal transcribed spacer 1 of rDNA. Int J Parasitol 2001, 31:610-614.

12. Hargrove JW, Langley PA: Sterilizing tsetse in the field: a successful field trial. Bull Entomol Res 1990, 80:397-403.

13. Thumbi SM, McOdimba FA, Mosi RO, Jung'a JO: Comparative evaluation of three PCR base diagnostic assays for the detection of pathogenic trypanosomes in cattle blood. Parasit Vectors 2008, 1:46.

14. Cortez AP, Rodrigues AC, Garcia HA, Neves L, Batista JS, Bengaly Z, Paiva F, Teixeira MMG: Cathepsin L-like genes of Trypanosoma vivax from Africa and South America - characterization, relationships and diagnostic implications. Mol Cell Probes 2009, 23:44-51 
15. Masiga DK, Smyth AJ, Hayes P, Bromidge TJ, Wendy CG: Sensitive detection of trypanosomes in tsetse flies by DNA amplification. Int J Parasitol 1992, 22:909-918.

16. Konnai S, Mekata H, Mingala CN, Abes NS, Gutierrez CA, Herrera JR, Dargantes AP, Witola WH, Cruz LC, Inoue N, Onuma M, Ohashi K: Development and application of a quantitative real-time PCR for the diagnosis of Surra in water buffaloes. Infect Genet Evol 2009, 9:449-452.

17. Radwanska M, Chamekh M, Vanhamme L, Claes F, Magez S, Magnus E, De Baetselier P, Pays E: The Serum Resistance-Associated gene as a diagnostic tool for the detection of Trypanosoma brucei rhodesiense. AmJTrop Med Hyg 2002, 67:684-690.

18. Radwanska M, Claes F, Magez S, Magnus E, Perez-morga D, Pays E, Büscher $P$ : Novel primer sequences for Polymerase Chain Reaction-based detection of Trypanosoma brucei gambiense. Am J Trop Med Hyg 2002, 67:289-295.

19. Simo G, Asonganyi T, Nkinin SW, Njiokou F, Herder S: High prevalence of Trypanosoma brucei gambiense group 1 in pigs from the Fontem sleeping sickness focus in Cameroon. Vet Parasitol 2006, 139:57-66.

20. Njiokou F, Laveissie're C, Simo G, Nkinin S, Gre'baut P, Cuny G, Herder S: Wild fauna as a probable animal reservoir for Trypanosoma brucei gambiense in Cameroon. Infect Genet Evol 2006, 6:147-153.

21. Njiokou F, Nimpaye H, Simo G, Njitchouang GR, Asonganyi T, Cuny G, Herder S: Domestic animals as potential reservoir hosts of Trypanosoma brucei gambiense in sleeping sickness foci in Cameroon. Parasite 2010, 17:61-66.

22. Salim B, Bakheit MA, Kamau J, Nakamura I, Sugimoto C: Molecular epidemiology of camel trypanosomiasis based on ITS1 rDNA and RoTat 1.2 VSG gene in the Sudan. Parasit Vectors 2011, 4:31.

23. Knowles G, Betschart B, Kukla BA, Scott JR, Majiwa PA: Genetically discrete populations of Trypanosoma congolense from livestock on the Kenyan coast. Parasitology 1988, 6:461-474

24. Bengaly Z, Sidibe I, Ganaba R, Desquesnes M, Boly H, Sawadogo L: Comparative pathogenicity of three genetically distinct types of Trypanosoma congolense in cattle: clinical observations and haematological changes. Vet Parasitol 2002, 108:1-19.

25. Kalu AU, Oboegbulem SI, Uzoukwu M: Trypanosomosis in small ruminants maintained by low riverine tsetse population in central Nigeria. Small Rumin Res 2001, 40:109-115.

26. Herder S, Simo G, Nkinin S, Njiokou F: Identification of trypanosomes in wild animals from southern Cameroon using the polymerase chain reaction (PCR). Parasite 2002, 9:345-349.

27. Njiokou F, Simo G, Nkinin SW, Laveissière C, Herder S: Infection rate of Trypanosoma brucei s.l., T. vivax, T. congolense "forest type", and T. simiae in small wild vertebrates in south Cameroon. Acta Trop 2004, 92:139-146.

28. Authié E, Bringaud F, Bakalara N, Tétaud E, Baltz T: Trypanosomoses humaines et animales: maladie du sommeil et Nagana. Ann Inst Pasteur 1999, 10:27-50.

29. Nimpaye H, Njiokou F, Njine T, Njitchouang GR, Cuny G, Herder S, Asonganyi T, Simo G: Trypanosoma vivax, T. congolense "Forest Type" and T. simiae: Prevalence in domestic animals of sleeping sickness foci of Cameroon. Parasite 2011, 18:171-179.

30. Sidibe I, Bengaly Z, Boly H, Ganaba R, Desquesnes M, Sawadogo L: Differential Pathogenicity of Trypanosoma congolense subgroup: Implication for the strategic control of trypanosomiasis. Newsletter on Integrated Control of Pathogenic Trypanosomes and their Vectors (I.C.P.T.V) 2002, 6:33-35.

31. Bengaly Z, Sidibe I, Boly H, Sawadogo L, Desquesnes M: Comparative pathogenicity of three genetically distinct Trypanosoma congolensetypes in inbred Balb/c mice. Vet Parasitol 2002, 105:111-118.

32. Penchenier L, Bodo JM, Bureau PH, Morlais I, Grebaut P, Djoha S, Herder S: Utilisation de la PCR sur sang pour le diagnostic des trypanosomoses porcines. Bulletin de liaison et de documentation de l'OCEAC 1996, 29:50-53.

33. Ahmed AH, MacLeod TE, Hide G, Welburn CS, Picozzi K: The best practice for preparation of samples from FTA ${ }^{\circledR}$ cards for diagnosis of blood borne infections using African trypanosomes as a model system. Parasit Vectors 2011, 4:68.

34. Cox AP, Tosas O, Tilley A, Picozzi K, Coleman P, Hide G, Welburn SC: Constraints to estimating the prevalence of trypanosome infections in East African zebu cattle. Parasit Vectors 2010, 3:82.

35. Mekata H, Konnai S, Simuunza M, Chembensofu M, Kano R, Witola WH, Tembo M, Chitambo H, Inoue N, Onuma M, Ohashi K: Prevalence and
Source of Trypanosome Infections in Field-Captured Vector Flies (Glossina pallidipes) in Southeastern Zambia. J Vet Med Sci 2008, 70:923-928

36. Malele II, Magwisha HB, Nyingilili HS, Mamiro KA, Rukambile EJ, Daffa JW, Lyaruu EA, Kapange LA, Kasilagila GK, Lwitiko NK, Msami HM, Kimbita EN: Multiple Trypanosoma infections are common amongst Glossina species in the new farming areas of Rufiji district. Tanzania. Parasit Vectors 2011, 4:217.

doi:10.1186/1756-3305-5-217

Cite this article as: Nakayima et al:: Molecular epidemiological studies on animal trypanosomiases in Ghana. Parasites \& Vectors 2012 5:217.

\section{Submit your next manuscript to BioMed Central and take full advantage of:}

- Convenient online submission

- Thorough peer review

- No space constraints or color figure charges

- Immediate publication on acceptance

- Inclusion in PubMed, CAS, Scopus and Google Scholar

- Research which is freely available for redistribution

Submit your manuscript at www.biomedcentral.com/submit
C BioMed Central 